\title{
O BRINCAR E A CULTURA: JOGOS E BRINCADEIRAS NA CIDADE DE MORRETES NA DÉCADA DE 1960
}

\author{
Álvaro M. P. Alves \\ Gilberto Gnoato
}

\begin{abstract}
RESUMO. O presente artigo busca discutir a relação entre brincadeira e cultura através das memórias e relatos de um morador da cidade histórica de Morretes, situada na microrregião litorânea paranaense. A metodologia empregada caracterizase como um estudo de caso, e a técnica de coleta de dados escolhida foi a entrevista semi-estruturada e pesquisa bibliográfica em acervo da Casa Rocha Pombo - Secretaria de Cultura e Esportes do município. Pôde-se concluir que a relação entre brincadeira e cultura pode ser enxergada sob vários aspectos, não devendo ser ignorada ou relegada como uma atividade secundária, seja do ponto de vista social seja do individual.
\end{abstract}

Palavras-chave: brincadeiras, cultura, história dos jogos.

\section{PLAYS AND CULTURE: GAMES AND TRICKS IN THE CITY OF MORRETES IN THE 60'S}

\begin{abstract}
The present article aims at discussing the relation between games and culture through the memories and stories of an inhabitant of the historical city of Morretes, Paraná state, which is located in the coastal micro region of Paraná. The methodology applied is of semi-structured interviews and bibliographical research in the archives of Casa Rocha Pombo Secretariat of Culture and Sports of the city of Morretes. It was observed that the relation between plays and culture can be viewed under several aspects, and it should be ignored or relegated as a secondary activity, either fromthe social or individual point of view.
\end{abstract}

Key words: tricks, culture, history of games.

O fenômeno da brincadeira há muito vem sendo investigado por pesquisadores da Psicologia (psicanalistas, behavioristas, cognitivistas), da Pedagogia e de disciplinas correlatas (Filosofia da Educação, Antropologia), como demonstram os trabalhos de Brougère (1995;1997) e Geertz (1989).

O presente trabalho buscará uma aproximação entre as diferentes contribuições das Ciências Humanas no estudo da brincadeira e sua relação com a cultura, mediante o estudo dos jogos e brincadeiras realizados na década de 1960 na cidade histórica de Morretes. Para tal, valemo-nos de um estudo de caso, ancorado nos relatos de ex-morador que passou sua infância da cidade na mesma década.

Segundo Triviños (1987): “(...) o estudo de caso é uma categoria de pesquisa cujo objeto é uma unidade que se analisa profundamente" (p. 133). O caso a ser pesquisado deve apresentar certa representatividade perante a população à qual pertence, o que, no caso do sujeito entrevistado (J.), diz respeito ao fato de o primeiro aparelho de televisão da cidade ter sido adquirido por seu pai, alterando a rotina das crianças de sua rua no que tange às atividades lúdicas.

\section{O BRINCAR E A CULTURA}

A brincadeira, entendida em seu aspecto livre ou sob a forma de jogo com regras, possui uma função simbólica e funcional. Para Brougère $(1995,18)$ "elas se fundem, o valor simbólico é a função". Ainda para esse autor, a brincadeira só existe na liberdade que a

\footnotetext{
Psicólogo, mestrando em Psicologia da Infância e Adolescência pela Universidade Federal do Paraná.

Endereço para correspondência: Av. Tio Ribas, 464-Centro, CEP 86990-000, Marialva-PR. E-mail alvaromarcel@yahoo.com

\#. Psicólogo, professor da Universidade Tuiuti do Paraná, especialista em Antropologia e mestrando em Psicologia da Infância e Adolescência pela Universidade Federal do Paraná.
} 
criança tem de iniciativa, opinião compartilhada por Vygotsky, que acredita na atividade imaginária como critério de diferenciação do brincar em relação a outras atividades realizadas pela criança.

Já o conceito de cultura, na concepção de Valsiner (1988), refere-se à organização estrutural de normas sociais, rituais, regras de conduta e sistemas de significado compartilhados pelas pessoas que pertencem a um certo grupo etnicamente homogêneo. Há duas facetas da cultura que são indistinguíveis: a cultura como entidade coletiva (significados compartilhados coletivamente) e a cultura como entidade pessoal (versão pessoal).

As crianças entram em contato o tempo todo, durante a brincadeira, com signos produzidos pela cultura à qual pertencem. Para Brougére (1997), a brincadeira de casinha, os brinquedos de guerra, os heróis da televisão ou a sandaliazinha da dançarina de axé são elementos que encerram em si significados e ideologias. Neste sentido é que ocorre a bidirecionalidade da transmissão cultural, pois a atividade de brincar da criança é estruturada conforme os sistemas de significado cultural do grupo a que ela pertence. Mas, ao mesmo tempo, esta atividade é reorganizada no próprio ato de brincar da criança, de acordo com o sentido particular por ela atribuído às suas ações, em interação com seus pares ou com os membros mais competentes de sua cultura. Nesse processo, tanto os significados coletivos quanto os sentidos pessoais são remodelados e redefinidos continuamente.

O jogo e o brincar supõem uma relação dual, a criança pode brincar com os significados para mediar simbolicamente a internalização da cultura, que promove saltos qualitativos no seu desenvolvimento. Segundo Araújo, Almeida e Ferreira (1998), o adulto deve fortalecer a consciência de si na criança, atribuindo um sentido externo ao brincar, e à medida que o jogo se torna um marco na atividade simbólica da criança, o adulto deixa de ser necessário para sua plena satisfação.

A assimilação da cultura, mediada pela brincadeira, possui uma função subjetiva, em que a criança resgata, organiza e constitui sua subjetividade (Araújo e cols,1998). Esta função da brincadeira corresponde ao que Valsiner (1988) denomina "entidade pessoal" da cultura.

Para os autores da Psicologia Soviética (Vygotsky, 1984; Leontiev, 1988; Elkonin, 1998), a atividade lúdica surge para resolver uma contradição, qual seja a discrepância entre o desejo de agir sobre o objeto e o domínio das operações necessárias para a execução desta ação. Esses autores, fortemente influenciados pelo materialismo dialético, vão defender que a humanização se dá a partir de dois elementos básicos: o instrumento e o signo. O primeiro age sobre os objetos e o segundo, sobre o psiquismo. Estes autores vão defender, conforme Leontiev (1988, p. 127), “o desenvolvimento como caracterizado por rupturas e desequilíbrios, com os adultos procurando dar significados às ações das crianças". A cultura, neste sentido, se configuraria como um "palco de negociações" (Rego, 1995, p. 55), onde a linguagem seria o fator mediador dos signos produzidos pela cultura.

A linguagem, como mediadora da cultura, forneceria três possibilidades de entendermos a brincadeira sob um ponto de vista histórico-cultural. A linguagem possibilita à criança: a) operar na ausência do objeto; b) generalizar e categorizar os objetos com que entra em contato; e c) comunicação que garante a conservação e transmissão de informações e experiências. Esta última é característica de crianças em idade escolar. Ainda para estes autores, a situação imaginária é sempre, também, "uma situação de relações humanas nela desenvolvida" (Leontiev, 1988,141).

Para Vygotsky (1984), o jogo facilita o desenvolvimento da imaginação e da criatividade. A criança em idade pré-escolar experimenta necessidades irrealizáveis, aparecendo o brinquedo e a atividade lúdica, com seu conteúdo imaginário, como possibilidade de realização dos desejos irrealizáveis. Vygotsky (1984) enxergará no brinquedo uma contribuição para o desenvolvimento inclusive da língua escrita, já que nele ocorre uma representação do significado. Outro fator ressaltado pelo autor diz respeito à presença de regras na brincadeira: qualquer forma de brinquedo imaginativo contém regras "a priori", embora não seja uma situação de jogo com regras formais estabelecidas.

Um autor da chamada Escola de Frankfurt, Benjamim (1984), analisando a obra de Karl Gröber (1899), diz que "o brinquedo é um mudo diálogo da criança com o seu povo" (p. 74). Mesmo afastado da Psicologia Histórico-Cultural no interesse teórico, Benjamim se aproxima de Leontiev à medida que conclui: "a brincadeira determina o conteúdo imaginário, não o contrário" (p. 69). Para esse autor, brincar significa sempre libertação. Neste sentido, Benjamim escreverá: “A banalização de uma existência insuportável contribuiu consideravelmente para o crescente interesse que jogos e brinquedos infantis passaram a despertar após o final da guerra"(p. 64). 
A relação da brincadeira e seu representante material (brinquedo) com a cultura é visto por Benjamim atrelada à função da imaginação no desenvolvimento da criança, na sua relação com os brinquedos. Por este motivo, afirmará que, quanto mais a imitação se anuncia nos brinquedos, tanto mais estes se desviam da brincadeira viva: "A essência do brincar não está no 'fazer como se', mas um 'fazer sempre de novo', transferência da experiência mais comovente em hábito" (Benjamim, 1984,75).

Até agora fizemos um percurso teórico para entendermos a relação entre brincadeira e cultura, que nos aproximou da Psicologia Histórico-Cultural, da Escola de Frankfurt e da Filosofia (através de Brougére). Cabe agora desenvolvermos um pouco a contribuição da Psicanálise para o estudo da brincadeira e de sua relação com a cultura. Neste sentido, as obras de Bettelheim (1988) e Winnicott (1975) vêm ao encontro de nosso objetivo.

Para a psicanálise, a brincadeira é um veículo para se chegar ao inconsciente. Freud (1920/1995) já havia chegado a esta conclusão quando escreveu o relato conhecido como fort da, presente no trabalho Além do Principio do Prazer, onde analisa um jogo de seu neto com um carretel. Seus sucessores desenvolveram uma teoria e técnica visando ao trabalho psicoterápico, e a brincadeira passou a ser indispensável para o sucesso da psicoterapia de crianças. Caberá a Winnicott (1975) compreender a brincadeira como uma atividade própria e não como instrumento para algum outro objetivo.

Bettelheim (1988) escreve que a brincadeira tem uma motivação interna, que corresponderia a uma ansiedade ou desejo, se configurando como um exercício de entendimento do mundo. Por isso entende a brincadeira compulsiva como representação de uma luta da criança para superar uma situação de dificuldade.

Para esse autor, a brincadeira é tão importante no desenvolvimento da criança, que sem ela o intelecto não se desenvolveria, pois a brincadeira possui uma função cognitiva e outra pulsional:

Mas a brincadeira tem duas facetas adicionais, uma dirigida para o passado e outra para o futuro (...) a brincadeira permite que a criança resolva de forma simbólica problemas não resolvidos do passado e enfrente direta ou simbolicamente questões do presente (Bettelheim, 1988,144-145).

Seguindo o raciocínio acima, o autor afirma que crianças que não têm grandes oportunidades de brincar e com as quais raramente se brinca sofrem graves interrupções ou reveses intelectuais, "porque na brincadeira e através dela, a criança exercita seus processos mentais" (Bettelheim, 1988,145).

Para Betelheim(1988), a grande contribuição da brincadeira na sua relação com a cultura é a capacidade da criança de aprender a não desistir aos primeiros sinais de fracasso, e sim, tentar e tentar novamente; ou seja, Bettelheim vê, na perseverança e no esforço tenaz, possibilidades de aprendizado cultural.

O interesse de Betelheim (1988) pelos jogos e brincadeiras também se manifestará no plano da relação destas atividades com a fantasia, a qual, em última instância, possibilita à criança a sublimação de suas pulsões agressivas no meio cultural, através dos jogos e brincadeiras de guerra. Sobre isso, nos diz:
$\mathrm{Na}$ imaginação, a criança pode ser absolutamente despótica, sem limitações para seu domínio. Mas quando começa a representar a fantasia, aprende depressa que mesmo soberanos absolutos estão sujeitos às limitações da realidade (...) aprenderá depressa que mesmo o imperador mais poderosamente imaginado só poderá reter o trono enquanto desfrutar da boa vontade dos súditos, que só pode brincar de soberano se tornar esse jogo atraente para seus companheiros (p. 150, sublinhado nosso).

A psicanálise desenvolvida por Betelheim enfoca a brincadeira como uma "ponte" para o aprendizado das leis culturais e sociais, ou seja, cuida de explicar a passagem do que Vygotsky (1984) chama "passagem do interpsicológico para o intrapsicológico", com a diferença de não enxergar esse movimento de forma dialética, e sim, dicotômica. Passemos agora à contribuição de outro autor da Psicanálise: Winnicott.

Winnicott (1975), assim como Freud, Betelheim, Lacan, Mannoni e Dolto, teve uma formação médica, tomando interesse pela pediatria logo nos primeiros anos de universidade. Desenvolveu uma teoria do desenvolvimento humano baseada na criatividade e no encontro do indivíduo com sua realidade cultural, não como sublimação (como afirmava Freud, Betelheim e Klein), mas como um processo de desinvestimento narcísico, tendo a brincadeira papel fundamental nesse desenvolvimento: "O jogo e a brincadeira devem ser estudados como temas específicos, que não correspondem ao conceito de sublimação das pulsões" (Winnicott, 1975, p. 56).

Winnicott destaca a ausência de uma verdadeira concepção de jogo na literatura analítica. Criticará Melanie Klein por ela atrelar a brincadeira aos conteúdos inconscientes de forma direta, como se a 
brincadeira estivesse única e exclusivamente à mercê das instâncias psíquicas. ${ }^{1}$ Neste sentido, Winnicott (1975,56) escreve: "Embora ela (Klein), se tenha ocupado da brincadeira, interessou-se quase unicamente pelo seu aspecto instrumental".

Não podemos pensar a noção e o papel atribuídos por Winnicott à brincadeira, sem compreendermos que o fenômeno da brincadeira está associado à importância atribuída pelo autor à criatividade. $\mathrm{O}$ jogo e a brincadeira são, para Winnicott, como nos lembra Brougère (1995, p. 97): "atos criativos e livres que emanam do indivíduo e não da sociedade, seja através de regras estabelecidas ou de uma organização". Isso não quer dizer alienação. Winnicott (1985) acredita que "todo indivíduo deve encontrar um lugar de onde operar no mundo". Esse "lugar" é propiciado pelas primeiras experiências, devendo haver um espaço nem subjetivo nem objetivo para se inserir esta experiência. Winnicott chama este espaço de espaço potencial, que deverá ser preenchido, num primeiro momento, por um objeto transicional. Esse espaço potencial é o espaço do imaginário, do jogo. É nesse espaço criado pelo bebê para aceitar estar sozinho que virá alojar-se a experiência cultural e artística, ou nos dizeres do próprio Winnicott: "se o objeto transicional perde sua significação, é porque os fenômenos transicionais tornam-se difusos e se estendem por todo o domínio cultural" (Winnicott, 1975,13).

Se fôssemos tentar esquematizar o que Winnicott chama de desenvolvimento normal, teríamos: a) a inauguração dos fenômenos transicionais, com a utilização de um objeto transicional; b) o início do brincar; c) o brincar compartilhado; e d) a experiência cultural, com o indivíduo investindo e compartilhando das conquistas de sua cultura.

O pensamento sobre o jogo e o brincar, através de Winnicott, encontra-se bastante ligado ao horizonte inaugurado pelo romantismo. Mas a Psicanálise, no que concerne ao jogo, não se originou neste movimento de pensamento, mas explorou-lhe novos aspectos, como nos lembra Brougère (1995).

Percorremos até aqui um caminho que nos levou da Psicologia Histórico-Cultural à Psicanálise, passando pela Escola de Frankfurt e Filosofia. O leitor poderá achar estranha a ausência de um autor clássico na abordagem da relação entre jogo e cultura, qual seja, Huizinga. O motivo é simples: Homo Ludens (1946) é considerada uma das obras mais importantes

\footnotetext{
Elkonin (1983) também fará uma crítica à concepção de jogo kleiniano, colocando-a como uma concepção idealista de desenvolvimento, chegando a citar pesquisas experimentais que contrariam os pressupostos teóricos da análise kleiniana.
}

na Filosofia da História no século XX, conforme apontam Eco (1985) e Lisboa (1991), merecendo um estudo à parte, por sua grandeza e profundidade.

Sobre a obra de Huizinga (1946), podemos salientar que ele toma o jogo em sua dimensão cultural e não biológica, estudando-o de um ponto de vista histórico, não científico. Para ele, nas raízes do homem está o gosto de se relacionar com o acaso, com o imponderável; o homem é "dado a brincar". Mas acaba concluindo que o homem lúdico, que floresceu até o século XVIII, entrou depois em declínio, surgindo agora na madrugada do século do lazer. Huizinga relaciona cultura e vida: "o jogo se estabelece logo como forma de cultura (...). As características do jogo são as mesmas da cultura, por conseguinte, a cultura desde a Antigüidade, manifestase como jogo" (confome citado por Eco, 1985, p. 276). Portanto, acaba fazendo uma teoria do comportamento lúdico, não do jogo, não estudando, conforme assinala Eco, o jogo jogante, e sim, o jogo jogado.

\section{METODOLOGIA}

\section{$O$ ator: perfil do entrevistado}

Foram realizadas duas entrevistas semiestruturadas com um morador da cidade de Morretes, cada uma com a duração de uma hora e meia.

Segundo Triviños (1987): "A entrevista semiestruturada, ao mesmo tempo que valoriza a presença do investigador, oferece todas as perspectivas possíveis para que o informante alcance a liberdade e a espontaneidade necessárias, enriquecendo a investigação" (p. 146). Sendo o estudo de caso uma categoria de pesquisa em que se busca analisar profundamente uma unidade, a entrevista semiestruturada valoriza a presença do investigador, que norteia a entrevista de acordo com os objetivos traçados no início do trabalho.

O entrevistado chama-se José, nasceu na cidade de Morretes no ano de 1956, tem duas irmãs e um irmão. Passou sua infância e adolescência na cidade, saindo dela para prestar o serviço militar obrigatório. Reside atualmente em Curitiba, onde exerce a profissão de engenheiro químico, mantendo contatos periódicos com a cidade de Morretes.

Sua escolha se deveu ao fato de José residir em Curitiba, facilitando nossos encontros. José é filho de um ex-juiz, morador influente, na década de 1960, na comunidade morretense. Teve uma infância que classifica de "livre", pois a posição social de sua família lhe possibilitou conviver com crianças de 
diferentes classes sociais, principalmente após a aquisição de uma TV por parte de seu pai, segundo José, a primeira televisão do bairro.

Não pretendemos traçar uma história de vida de José, mas sim, através de seus relatos, estabelecer uma relação entre brincadeira e cultura, tendo como referencial uma comunidade tradicional, não industrial. A entrevista semi-estruturada seguiu um roteiro que contou com as seguintes perguntas:

1. Como você se lembra da cidade Morretes na década de 1960 ?

2. Descreva o bairro em que morava, inclusive sua rua.

3. Quais suas brincadeiras preferidas? De quais você se lembra?

4. Do que você e seus amigos brincavam após a chegada da televisão em Morretes?

\section{Contextualizando os relatos}

Os relatos do entrevistado têm uma circunferência histórica, onde a realidade e a percepção do sujeito acerca do tempo de infância sofrem influência do seu momento presente, ou seja, são ressignificadas. Para compreendermos a vida de uma criança em Morretes na década de 1960, é preciso que digamos como era a sociedade morretense nesse período - sua população, costumes locais, vida econômica. Esses fatores podem ajudar o leitor a situar-se melhor diante dos relatos, pois o contexto dado pela história da cidade nos possibilita compreender que condições havia que permitiam o brincar.

Morretes possuía, segundo o entrevistado, cerca de 12.000 habitantes no ano de 1965, informação confirmada por nós em consulta à Casa Rocha PomboSecretaria de Cultura e Esporte da cidade de Morretes. José nos disse que a cidade era extremamente calma, tranqüila, com as pessoas se sentando em cadeiras nas ruas, onde ficavam conversando por muito tempo. As casas eram encostadas umas nas outras e as pessoas se encontravam no final da tarde após o jantar para contar "causos". As famílias que moravam nas ruas mais centrais tinham o hábito de ir às praças para conversar. Os nomes das ruas eram sempre referentes a um morador conhecido ou às localidades principais: rua do colégio, da delegacia, da prefeitura; ou ainda, referentes a um fato histórico marcante, como acidentes, afogamento de crianças ou algo que tenha acontecido com um compadre.

Nos finais de semana, as famílias se aglomeravam nas chamadas prainhas, onde tomavam banho à beira do rio Nhundiaquara. A missa dominical é lembrada como uma obrigação sagrada para os morretenses da época. O espaço de maior convívio social é descrito pelo entrevistado como sendo a rua.

A igreja se situava num outeiro (pequeno morro), como descrito por Saint-Hilaire, naturalista francês que viveu de 1779-1853 e passou pelo litoral paranaense no ano de 1820. A igreja, mais propriamente o sino, representava uma referência, local onde inclusive se instalou o primeiro morador de Morretes, conforme assinala Vieira dos Santos (1851):

João de Almeida, Chéffe da família, fes sua casa de morada no alto da Igreja e próximo a ponte do Ribeirão outra morada chamada vulgarmente a casa da farinha, na qual tinha rôda e prénsa de a confecionar, e hum pequeno engênho de moêr Canna. (p.35)

\section{O grupo de brincadeiras}

José lembra-se dos jogos e brincadeiras de sua infância como feitos em grupo, na rua e no rio Nhundiaquara. O espaço da rua era visto como uma extensão da casa, da família, com os amigos representando muitas vezes uma fuga aos conflitos familiares:

Lembro-me de um episódio com 8-9 anos de idade em que briguei com meus pais, saí para a rua e só voltei ao anoitecer. Meus pais estavam no portão de casa, varrendo a calçada; quando passei por eles levei boas vassouradas.

Relata também que certa vez seu pai comprou a casa ao lado, a qual ficou durante três anos sendo utilizada somente para as brincadeiras dos irmãos, principalmente das meninas, que brincavam de casinha e boneca, segundo José, "brincadeiras de menina".

Outras lembranças de José referem-se às brincadeiras de empinar raia, conhecida como pipa ou papagaio, e arco e flecha:

(...) onde fazia-se a raia com uvá ou bambu e paina, a cola utilizada era feita com ovo de caramujo jatutá com farinha de trigo.Batia tudo e obtinha-se uma goma, que quando secava virava cola (...) era preciso ser criativo, nós inventávamos, pois os brinquedos industrializados não existiam para nós, dependíamos da tradição. Por exemplo, a luta de espada, arco e flecha (...) esse era tradição por causa dos índios. Latas de leite viravam carrinhos, usando barbante e prego, para o arco e flecha usávamos bambu.

José lembra-se de um tipo de brincadeira que seria semelhante ao que conhecemos hoje como 
tobogã, usando folhas de casca de coqueiro, palmeira imperial:

"Sentávamos como num trenó e éramos conduzidos pirambeira abaixo até o final de nossa rua".

Nos exemplos acima, vemos o valor atribuído por José à criatividade. Mesmo sem ter a consciência histórico-acadêmica do seu relato, José faz uma comparação com as brincadeiras atuais: "Hoje em dia as brincadeiras estão prontas, as crianças morretenses e de fora também, não são levadas a criar, pensar em um brinquedo, acho triste isso..." Outro morador que encontramos em uma das visitas à Casa Rocha Pombo, comentou que "as brincadeiras antigas estão se perdendo", deixando transparecer um saudosismo em relação à infância, lembrando espontaneamente, sem sugestão dos pesquisadores, outras brincadeiras, como as realizadas no rio Nhundiaquara.

Passemos agora à outra etapa do artigo, qual seja a influência da TV na construção da cultura infantil morretense.

\section{A influência da TV nas brincadeiras}

Os meios de comunicação de massa, principalmente a televisão, colaboraram para a criação e disseminação de uma representação de infância, uma concepção do que é a criança, e portanto, do que ela precisa. Segundo Gomes (2000, 93):

Entre nós, é interessante destacar a verdadeira competição que os veículos de comunicação, sobretudo a televisão, operam com o imaginário da população infantil. Enquanto objeto cultural, um real transformado a partir de uma imagem que os fabricantes de brinquedos têm de infância.

José relata o seguinte, sobre o primeiro aparelho de TV de seu bairro e um dos primeiros de Morretes, comprado por seu pai:

Por volta de 1965 meu pai comprou um televisor. No começo ele parecia a coisa mais hipnótica que aconteceu na cidade, como se uma pessoa visse uma 'visagem', uma coisa de outro mundo. Seu impacto foi imediato, as crianças se reuniam em torno de 20 , só para assistir a televisão, sobretudo os filmes de bang-bang. Os tiroteios e as flechas eram maravilhosos e nós começamos a imitá-los imediatamente. Algumas brincadeiras, como as de arco e flecha, foram substituídas pelas de bang-bang. Dois grupos eram formados, cada um se dividia em cantos opostos do terreno (.....). A intenção era "matar" o outro, como faziam os mocinhos do filme com os índios. Levamos tempo para perceber que aquilo era um filme, ficção, nós incorporamos os personagens da TV como se eles de fato existissem (...). Gritava-se "bam, bam' e o outro estava "morto".

A cultura pensada como um ethos, uma morada para o homem, se baseia sobretudo na tradição transmitida, principalmente de forma oral. Quando a TV penetra a vida das crianças morretenses, tem-se uma alteração deste ethos, passando a morada (os significados) das brincadeiras a uma repetição de modelos de uma outra cultura, neste caso, a norteamericana. O brinquedo aqui une as experiências das crianças com os símbolos (ou signos) de uma produção cultural, de uma indústria cultural, como aponta Gomes (2000, 93): "Visto dessa forma, a produção cultural dirigida à criança brasileira traz elementos que nos induzem a pensar no tipo de cidadão, no tipo de sociedade para qual ele está sendo formado".

O tipo de sociedade que queremos nem sempre nos é dado escolher, ele advém de uma consciência histórica, conforme por exemplo, o relato de José sobre o asfaltamento das ruas do centro histórico da cidade, substituindo o paralelepípedo existente:

Quando perguntei o porquê dessa atitude, responderam-me que nossas crianças precisavam de esportes modernos, como roller, patins, skates, por isso precisamos de asfalto, não de paralelepípedos (...). Achei um abuso! (...). Hoje em dia, as crianças não brincam mais de arco e flecha em Morretes. O significado daquela brincadeira se perdeu, acho que aquilo tudo deixou de ser referência para a nova geração.

\section{CONCLUSÃO}

A esta altura, podemos concluir que a relação entre brincadeira e cultura pode ser enxergada sob vários aspectos, não devendo ser ignorada ou relegada como uma atividade secundária, seja do ponto de vista social seja individual. Não por acaso, tratamos de enunciar as prerrogativas histórico-culturais e psicanalíticas acerca do brincar. Esta posição não vem ao encontro de tentativas ingênuas de aliar marxismo e psicanálise, tantas vezes criticadas por ambas as tendências de pensamento. Busca, sim, compreender como aspectos sociocognitivos, histórico-culturais e emocionais estão presentes na atividade lúdica desenvolvida pela criança, e que seu desenvolvimento 
vai depender em grande parte da capacidade de sua cultura absorver suas necessidades e desejos, tão particulares a esse período da vida.

A recuperação da memória de jogos e brincadeiras na década de 1960 numa cidade como Morretes nos possibilita entrar em contato com um período especial da história dos jogos, qual seja a entrada e influência da TV na cultura infantil morretense. $\mathrm{O}$ resgate dos jogos tradicionais infantis possibilita uma construção e reconstrução da identidade individual e coletiva, baseada na experiência, como nos mostra Benjamim (1984).

Ainda sobre a importância da recuperação da experiência através da memória, Silva, Garcia e Ferrari, $(1989,71)$ escrevem:

A perda da experiência, da possibilidade da reflexão, da memória como suporte da identidade, do enraizamento cultural e da participação no coletivo, o desaparecimento de todos esses elementos, resultado da modernização, significou o advento do indivíduo desmemoriado, sem vínculo com a tradição, que vive os sobressaltos e choques da vida cotidiana sem a possibilidade de reflexão.

Finalizamos nosso trabalho deixando a última palavra com o poeta, mais competente para expor as emoções, tão próximas do brinquedo e do brincar:

\section{RECORDO AINDA}

Recordo ainda... e nada mais me importa Aqueles dias de uma luz tão mansa Que me deixavam, sempre de lembrança, Algum brinquedo novo a minha porta... Eu quero meus brinquedos novamente! Sou um pobre menino....acreditai.... Que envelheceu, um dia, de repente!

(Mário Quintana)

\section{REFERÊNCIAS}

Araújo, C. M. M.;. (1998) O Brincar no desenvolvimento e na subjetividade infantil: tema para a atuação profissional. Em: Congresso Internacional de Psicanálise e suas Conexões. (Tomo II) Rio de Janeiro: Companhia de Freud.

Benjamim, W. (1984) Reflexões: A criança, o brinquedo e a educação. (M.V. Mazzari, Trad). São Paulo: Summus.

Bettelheim, B. (1988) Uma vida para seu filho: pais bons o bastante. (M. Sardinha \& M. H. Geordane, Trads). Rio de Janeiro: Campus.

Brougère, G. (1995) Brinquedo e cultura. São Paulo: Cortez.
Brougère, G. (1997) Jogo e educação. Porto Alegre: Artes Médicas.

Dicionário: A língua tupi na geografia do Brasil. (s/d) Curitiba: Banestado .

Elkonnin, D. (1998) Psicologia do jogo. (Á. Cabral, Trad.). São Paulo: Martins Fontes.

Eco, U., Huizinga e O. Jogo (1985). Em: Sobre os espelhos. São Paulo: Nova Fronteira.

Freud, S. (1995) Além do princípio do prazer. (J. Salomão Trad.), Edição Standard Brasileira das Obras Psicológicas Completas. (Vol. XVIII, pp. 17-79). Rio de Janeiro: Imago. (Originalmente publicado em 1920).

Geertz, C. (1989) A Interpretação das culturas. Rio de Janeiro: Guanabara Koogan.

Gomes, M. O. (2000) Jogo, educação e cultura: "senões e questões". Psicologia em Estudo.5, (2), 91-98.

Leontiev, A. (1988) Princípios psicológicos da brincadeira préescolar. Em: Desenvolvimento, linguagem e aprendizagem. (pp. 119-142). São Paulo: Ícone.

Lisboa, L. C. (1991) Homo Ludens. Em: Pequeno guia da literatura universal. (pp. 192-195). São Paulo: Círculo do Livro.

Rego, M. C. (1995) Vygotsky. Petrópolis: Vozes.

Saint-Hilaire, A. (1995) Viagem pela comarca de Curitiba. (C. L. Carollo Trad.) Curitiba: Fundação Cultural de Curitiba.

Silva, M. A. S. S., Garcia, M. A. L. e Ferrari, S. C. M. (1989) Memória e brincadeiras na cidade de São Paulo nas primeiras décadas do século XX. São Paulo: Cortez CENPEC.

Triviños, A. N. S. (1987) Introdução à pesquisa em ciências sociais: a pesquisa qualitativa em educação. São Paulo: Atlas.

Valsiner, J. (1988). Ontogeny of co-contruction of culture within socially organized environmental settings. Em J. Valsiner (Org.), Child developmental within culturally structured environments, (Vol. 2, pp. 283-297). New Jersey: Ablex Publishing Corporation.

Vieira dos Santos, A. (1950). Memória histórica da Villa de Morretes e do Porto Real. (Curitiba: Secção de História do Museu Paranaense - Círculo de Estudos) Bandeirantes. (Originalmente publicado em 1851)

Vygotsky, L. S. (1984) Formação social da mente. São Paulo: Martins Fontes.

Winnicott, D. W. (1975) O brincar e a realidade. Rio de Janeiro: Imago.

Winnicott, D. W. Por quê as crianças brincam? (1985) Em: $A$ criança e o seu mundo. (Á. Cabral, Trad.) Rio de Janeiro: Jorge Zahar.
Recebido em 21/10/2002 Revisado em 18/03/2003 Aceito em 30/05/2003 